\title{
Risk Factors for Surgical Site Infections in Patients Undergoing Emergency Surgery: A Single-centre Experience
}

\author{
ARISTEIDIS PAPADOPOULOS ${ }^{1}$, NIKOLAOS MACHAIRAS ${ }^{2}$, GERASIMOS TSOUROUFLIS ${ }^{2}$, \\ CHRISTOS CHOULIARAS ${ }^{1}$, ELENI MANIOTI ${ }^{1}$, DIMITRIOS BROUTAS ${ }^{1}$, STYLIANOS KYKALOS ${ }^{2}$, \\ GEORGE L. DAIKOS $^{3}$, MICHAEL SAMARKOS ${ }^{3}$ and CONSTANTINE VAGIANOS ${ }^{2}$ \\ ${ }^{1} 1$ st Department of Surgery, Nikaia General Hospital, Nikaia, Greece; \\ ${ }^{2} 2^{\text {nd }}$ Department of Propaedeutic Surgery, National and Kapodistrian University of Athens, Athens, Greece; \\ ${ }^{3} 1^{\text {st }}$ Department of Medicine, National and Kapodistrian University of Athens, Athens, Greece
}

\begin{abstract}
Background/Aim: Surgical site infections (SSI) are associated with increased morbidity and mortality, and they occur more frequently during unplanned emergency surgical (ES) procedures rather than elective. Our aim was to determine the incidence of SSI within our ES cohort and to identify risk factors for SSI. Patients and Methods: Data from consecutive patients undergoing ES in a single institution during a 5-year period were prospectively collected and analyzed. Results: A total of 838 consecutive patients were included. The median age was 52 (IQR=2571) years and some $368(44 \%)$ were female. 157 (18.7\%) of those patients developed SSI. The most commonly isolated pathogen was E. Coli (55.4\%) followed by Staphylococcus Aureus (40.1\%). The 30-day mortality rate of patients who presented SSIs was $14.6 \%$ compared to $6.8 \%$ of patients without SSI ( $p=0.002)$. Multivariable analysis showed that the type of wound, American Society of Anesthesiology score, severity and duration of surgery $>90 \mathrm{~min}$ were independent risk factors for the occurrence of SSI. Conclusion: Identification of modifiable causative factors for SSI within an ES unit is paramount as they can critically impact postoperative outcomes.
\end{abstract}

Surgical site infections (SSI) represent a major burden for surgical patients and are associated with increased morbidity, protracted hospital length of stay, higher intensive care unit

This article is freely accessible online.

Correspondence to: Prof. Michael Samarkos, MD, Ph.D., 1st Department of Medicine, National and Kapodistrian University of Athens, General Hospital Laiko, Ag. Thoma 17, 11527, Athens, Greece. Tel: +30 2107277000, e-mail: msamarkos@gmail.com

Key Words: Surgical wound infections, emergency surgery, risk factors, trauma, antibiotics, morbidity, mortality.
(ICU) admissions and hospital readmissions, as well as increased mortality and last but not least, increased economic costs (1). Over the past decades, prevention of SSIs has attracted substantial interest from surgeons, infection preventionists, and health care authorities (2). In particular, patients undergoing emergency surgery (ES) are at higher risk for developing SSIs compared to those undergoing elective surgery due to dirtier and more contaminated wounds. Notably, while SSIs in patients undergoing elective surgery may range from $1.5 \%$ to $5 \%$, in patients undergoing ES, SSIs may account for 7-32\% $(3,4)$. Patients undergoing ES have higher morbidity and mortality rates. In this context, predicting and preventing the occurrence of SSIs in these vulnerable patient groups are of cardinal importance.

A plethora of patient and procedure-related factors have been strongly associated with the occurrence of SSI over the past decades (5). Advanced age, poor nutritional status, increased body mass index (BMI), smoking, remote infections, and administration of immunosuppressive medication are amongst the most common patient-related risk factors for the occurrence of SSI. On the other hand, prolonged operative time, contaminated wound status, prophylactic administration of antibiotics, and emergency nature of surgery are among the most common procedure-related risk factors $(5,6)$.

Morbidity and mortality rates in these high-risk patients could be actively decreased by interventions focused on potentially modifiable risk factors for the development of SSI. For that reason, the objective of our study was to identify the incidence and risk factors of SSI within our ES cohort.

\section{Patients and Methods}

Study design. This study was a prospective, observational study, which was approved from the Institutional Review Board of "Agios Panteleimon" General Hospital of Nikea. A patient information sheet and an informed consent form were provided to patients eligible to be included in the study. Signed informed consent was 


\begin{tabular}{|c|c|c|c|}
\hline & Mild & Moderate & Severe \\
\hline Acute appendicitis & $\begin{array}{c}\text { Appendectomy for } \\
\text { inflammatory appendicitis }\end{array}$ & $\begin{array}{l}\text { Appendectomy for } \\
\text { supppurative } \\
\text { appendicitis }\end{array}$ & $\begin{array}{l}\text { Appendectomy } \pm \text { colectomy for } \\
\text { perforated appendicitis / } \\
\text { generalized peritonitis }\end{array}$ \\
\hline Acute cholecystitis & $\begin{array}{l}\text { Cholecystectomy for mild } \\
\text { cholecystitis }\end{array}$ & $\begin{array}{c}\text { Total/subtotal } \\
\text { cholecystectomy for } \\
\text { GB empyema }\end{array}$ & $\begin{array}{l}\text { Total/subtotal cholecystectomy for } \\
\text { GB perforation / biliary peritonitis }\end{array}$ \\
\hline Acute diverticulitis & - & $\begin{array}{c}\text { Primary repair/resection } \\
\text { for perforated bowel/ } \\
\text { local abcess }\end{array}$ & $\begin{array}{l}\text { Resection for perforated bowel / } \\
\text { generalized peritonitis }\end{array}$ \\
\hline $\begin{array}{l}\text { Gastrointestinal } \\
\text { perforation }\end{array}$ & $\begin{array}{l}\text { Primary repair for recent } \\
\text { perforation / no abcess- } \\
\text { peritonitis }\end{array}$ & $\begin{array}{l}\text { Primary repair/resection } \\
\text { for local abcess }\end{array}$ & Resection for generalized peritonitis \\
\hline Obstructive ileus & $\begin{array}{l}\text { Adhesiolysis } \\
\text { (no ischaemia) }\end{array}$ & $\begin{array}{c} \pm \text { Resection } \\
\text { (ischaemia present) }\end{array}$ & $\begin{array}{l}\text { Resection for perforation/ } \\
\text { generalized peritonitis }\end{array}$ \\
\hline Strangulated hernia & $\begin{array}{l}\text { Simple rapair } \\
\text { (no ischaemia) }\end{array}$ & $\begin{array}{c} \pm \text { Resection } \\
\text { (ischaemia present) }\end{array}$ & Resection for perforated bowel \\
\hline $\begin{array}{l}\text { Trauma with } \\
\text { haemorrhage }\end{array}$ & - & $\begin{array}{l}\text { Repair/resection for } \\
\text { single organ trauma }\end{array}$ & Resection for multiorgan trauma \\
\hline $\begin{array}{l}\text { Trauma with } \\
\text { peritonitis }\end{array}$ & - & $\begin{array}{l}\text { Primary repair/resection } \\
\text { for localized peritonitis }\end{array}$ & Resection for generalized peritonitis \\
\hline $\begin{array}{l}\text { Upper gastrointestinal } \\
\text { bleeding }\end{array}$ & - & $\begin{array}{l}\text { Primary repair/short } \\
\text { segment resection }\end{array}$ & Extended resection \\
\hline $\begin{array}{l}\text { Lower gastrointestinal } \\
\text { bleeding }\end{array}$ & - & Short segment resection & Extended resection \\
\hline Vascular ischaemia & - & Short segment resection & Extended resection \\
\hline
\end{tabular}

Figure 1. Study classification of severity of surgical procedures with examples.

obtained from each included patient. All patient data were deidentified, and the authors assumed written responsibility for the protection of patient data according to the regulations of the Hellenic Data Protection Authority.

Setting. The study took place at the "Agios Panteleimon" General Hospital of Nikea from January 1st, 2010 to December $31^{\text {st }}, 2014$. Data were collected with the use of a prospectively maintained Excel spreadsheet (Microsoft, Redmond, WA, USA), starting immediately after institutional review board (IRB) approval was obtained.

Inclusion and exclusion criteria. Consecutive patients who underwent ES at the First Surgical Department of "Agios Panteleimon" General Hospital of Nikea were considered eligible for inclusion. We have excluded patients which underwent ES for skin and soft tissue infections, as there is no standard definition of SSI for these operations, given the difficulty to assess the presence of SSI in soft tissue infections.

Definitions. We have used the Centers for Disease Control and Prevention/National Healthcare Safety Network (CDC/NHSN) criteria of SSI (7). For surgical wound class we have used the standard definitions of American College of Surgeons Committee on Control of Surgical Infections (8).

Recorded variables. The following variables were recorded: a) Patient information (demographics and personal history): gender, age, body mass index (BMI), smoking status, presence of diabetes mellitus, coronary heart disease, heart failure, chronic respiratory failure and chronic renal failure, administration of anticoagulants, and American Society of Anesthesiology score (9). b) Data of the surgery: surgical wound class, severity and duration of operation, perioperative red blood cell unit (RBCU) transfusions, antimicrobials before surgery, other remote infection, chemoprophylaxis or antimicrobial treatment, and intensive care unit (ICU) admission. c) SSI Data: SSI classification, pathogenic cause of SSI, antimicrobial treatment administered, other postoperative infections, postoperative complications (graded according to Clavien-Dindo classification) (8) d) Outcomes: length of hospital stay, readmission, and 30-day mortality. The severity of the surgical procedure performed was independently assessed by two surgeons (AP and CV) based on predetermined criteria (Figure 1). The grading of the surgical wound class in each patient was similarly independently assessed by the same two surgeons (10).

Statistical analysis. Statistical analysis was performed using IBM SPSS Statistics for Windows, Version 26.0 (IBM, Armonk, NY, USA). Chi-square test and Fisher's exact test were used for comparisons among groups with categorical variables. Logistic regression analysis was used for multivariable analysis of risk factors for SSI. All the tests were two-tailed. Results were considered statistically significant if the $p$-value was less than 0.05 .

\section{Results}

Patient characteristics. A total of 838 patients who underwent ES during the study period were included. The mean age was 50.9 years $(\mathrm{SD}=23.0)$ and $368(44 \%)$ of them were female. One hundred and fifty-five $(18.7 \%)$ of these patients developed SSI. Characteristics of patients with and 


\begin{tabular}{|c|c|c|c|c|c|}
\hline & & \multicolumn{3}{|c|}{ Presence of SSI } & \multirow[b]{2}{*}{$p$-Value $\S$} \\
\hline & & $\begin{array}{c}\text { Total } \\
(\mathrm{n}=835)\end{array}$ & $\begin{array}{c}\text { No } \\
(\mathrm{n}=678)\end{array}$ & $\begin{array}{c}\text { Yes } \\
(\mathrm{n}=157)\end{array}$ & \\
\hline Gender & Female & $368(44)$ & $306(45.1)$ & $62(39.5)$ & 0.210 \\
\hline Age & Years (mean - SD) & $50.1(23.0)$ & $48.1(23.0)$ & $63.2(18.6)$ & $<0.001 *$ \\
\hline BMI & $\mathrm{Kg} / \mathrm{m}^{2}($ mean $-\mathrm{SD})$ & $26.1(5.2)$ & $25.7(4.8)$ & $27.9(6.2)$ & $<0.001 *$ \\
\hline \multirow[t]{4}{*}{ Smoking } & Current smoker & $337(40.3)$ & $263(38.8)$ & $74(47.1)$ & 0.239 \\
\hline & Ex-smoker & $75(9)$ & $61(9.1)$ & $14(8.9)$ & \\
\hline & Non-smoker & $424(50.7)$ & $355(52.3)$ & $69(43.9)$ & \\
\hline & Unknown & $1(0.1)$ & $1(0.1)$ & $0(0)$ & \\
\hline \multirow[t]{4}{*}{ Comorbidities } & Diabetes & $116(13.9)$ & $73(10.8)$ & $43(27.4)$ & $<0.0001$ \\
\hline & CHD - CHF & $121(14.5)$ & $84(12.4)$ & $37(23.6)$ & $<0.0001$ \\
\hline & CKD & $29(3.5)$ & $22(3.2)$ & $7(4.5)$ & 0.445 \\
\hline & COPD & $59(7.1)$ & $38(5.6)$ & $21(13.4)$ & 0.001 \\
\hline \multirow[t]{3}{*}{ Medication } & Anticoagulants & $42(5)$ & $29(4.3)$ & $13(8.3)$ & 0.038 \\
\hline & Antiplatelets & $71(8.5)$ & $48(7.1)$ & $23(14.6)$ & 0.002 \\
\hline & Steroids & $37(4.4)$ & $23(3.4)$ & $14(8.9)$ & 0.002 \\
\hline \multirow[t]{5}{*}{ ASA } & 1 & $223(26.6)$ & $216(31.8)$ & $7(4.5)$ & $<0.0001$ \\
\hline & 2 & $443(52.9)$ & $357(52.5)$ & $86(54.8)$ & \\
\hline & 3 & $146(17.4)$ & $85(12.5)$ & $61(38.9)$ & \\
\hline & 4 & $22(2.6)$ & $19(2.8)$ & $3(1.9)$ & \\
\hline & 5 & $3(0.4)$ & $3(0.4)$ & $0(0)$ & \\
\hline Preop LOS >1 day & & $254(30.3)$ & $175(25.7)$ & $79(50.3)$ & $<0.0001$ \\
\hline
\end{tabular}

SSI: Surgical site infection; BMI: body mass index; CHD: coronary heart disease; CHF: Congestive heart failure; CKD: chronic kidney disease; COPD: chronic obstructive pulmonary disease; ASA: American society of anesthesiology score, ${ }^{\S} p$-Value for Chi-square test, ${ }^{*} p$-Value for MannWhitney $U$-test.

without SSI are shown in detail in Table I. Characteristics associated with the presence of SSI were older age, higher BMI, presence of diabetes, coronary heart disease or congestive heart failure, and chronic obstructive pulmonary disease. Patients with SSI were more frequently receiving anticoagulants, aspirin, and steroids compared to the non-SSI group, confirming the higher comorbid state of these patients. Finally, patients with SSI had significantly higher ASA score and were more frequently admitted to our hospital $>1$ day before undergoing ES.

Perioperative outcomes. The indications for ES as well as perioperative outcomes are shown in Table II. The primary wounds of patients who developed SSI were more commonly dirty or contaminated, compared to the non-SSI groups of patients $(p<0.0001)$, whilst they also underwent more severe procedures compared to the latter $(p<0.0001)$. Surgical procedures lasted more frequently longer than 90 minutes in patients who eventually developed SSI $(p<0.0001)$, whilst these patients were more frequently transfused with $>2 \mathrm{RBC}$ units. The most common type of infection was superficial $(60.5 \%)$, followed by deep incisional (21.7\%), and organ/space infections $(17.8 \%)$. The most commonly isolated pathogen was E. Coli (55.4\%) followed by Staphylococcus aureus (40.1\%), Enterococcus spp. (21.6\%), Pseudomonas aeruginosa (19.7\%), Klebsiella spp. (15.4\%), coagulasenegative staphylococci (12.7\%), and Acinetobacter spp. $(6.4 \%)$. Patients who developed SSI had significantly higher CD complications (>grade II) $(p<0.0001)$, and were more frequently reoperated $(p<0.0001)$ and readmitted $(p<0.0001)$, compared to non-SSI patients. Patients not developing SSI had a median length of hospital stay of 5 days (IQR=5-6), while those who developed SSI had a median stay of 17 (IQR=14-23) days. The 30-day mortality rate of patients who presented SSIs was higher $(23 / 157,14.6 \%)$ compared to $(47 / 681,6.8 \%)$ that of patients without SSI $(p=0.002)$.

Multivariable analysis. All variables associated with SSI in univariate analysis were entered into a multivariable logistic regression model in which the outcome was the presence of SSI. Ordinal variables were transformed into binary: ASA score 1 vs. 2-5, severity mild vs. moderate and severe, wound category clean vs. non-clean categories. Logistic regression analysis showed that non-clean wound class [odds ratio $(\mathrm{OR})=3.312,95 \%$ confidence intervals $(\mathrm{CI})=1.266-8.663)$, $p=0.015]$, ASA score $\geq 2(\mathrm{OR}=3.895,95 \% \mathrm{CI}=1.702-8.914$, $p=0.001)$, moderate or higher severity $(\mathrm{OR}=4.735$, $95 \% \mathrm{CI}=2.501-8.963, p<0.0001)$ and duration of surgery $>90$ $\min (\mathrm{OR}=1.876,95 \% \mathrm{CI}=1.186-2.969, \quad p=0.007)$ were independent risk factors for the occurrence of SSI (Figure 2). 
Table II. Perioperative characteristics.

\begin{tabular}{|c|c|c|c|c|c|}
\hline & & \multicolumn{3}{|c|}{ Presence of SSI } & \multirow[b]{2}{*}{$p$-Value } \\
\hline & & $\begin{array}{l}\text { Total } \\
\text { n }(\%)\end{array}$ & $\begin{array}{l}\text { No } \\
\text { n }(\%)\end{array}$ & $\begin{array}{l}\text { Yes } \\
\mathrm{n}(\%)\end{array}$ & \\
\hline \multirow[t]{7}{*}{ Indication for surgery } & GI bleeding & $14(1.7)$ & $5(0.7)$ & $9(5.7)$ & \multirow[t]{7}{*}{$<0.0001$} \\
\hline & Obstructive Ileus & $189(22.6)$ & $147(21.6)$ & $42(26.8)$ & \\
\hline & Intra-abdominal infection* & $564(67.4)$ & $465(68.4)$ & $99(63.1)$ & \\
\hline & Other & $17(2)$ & $17(2.5)$ & $0(0)$ & \\
\hline & Trauma with bleeding & $40(4.8)$ & $36(5.3)$ & $4(2.5)$ & \\
\hline & Trauma with peritonitis & $5(0.6)$ & $5(0.7)$ & $0(0)$ & \\
\hline & Vascular ischemia & $8(1)$ & $5(0.7)$ & $3(1.9)$ & \\
\hline \multirow[t]{4}{*}{ Wound category } & Clean & $116(13.9)$ & $111(16.3)$ & $5(3.2)$ & \multirow[t]{4}{*}{$<0.0001$} \\
\hline & Clean-contaminated & $382(45.6)$ & $342(50.3)$ & $40(25.5)$ & \\
\hline & Contaminated & $297(35.5)$ & $212(31.2)$ & $85(54.1)$ & \\
\hline & Dirty & $42(5)$ & $15(2.2)$ & $27(17.2)$ & \\
\hline \multirow[t]{3}{*}{ Severity } & Mild & $388(46.4)$ & $374(55)$ & $14(8.9)$ & \multirow[t]{3}{*}{$<0.0001$} \\
\hline & Moderate & $259(30.9)$ & $206(30.2)$ & $53(33.8)$ & \\
\hline & Severe & $190(22.7)$ & $100(14.7)$ & $90(57.3)$ & \\
\hline Duration $>90 \mathrm{~min}$ & & $370(44.2)$ & $253(37.2)$ & $117(74.5)$ & $<0.0001$ \\
\hline Transfusion of $>2 \mathrm{RBCU}$ & & $73(8.7)$ & $43(6.3)$ & $30(19.1)$ & $<0.0001$ \\
\hline \multirow{4}{*}{$\begin{array}{l}\text { Pre-operative } \\
\text { antimicrobials }\end{array}$} & Prophylaxis & $205(24.5)$ & $179(26.3)$ & $26(16.6)$ & \multirow[t]{4}{*}{$<0.0001$} \\
\hline & Treatment for remote infection & $25(3)$ & $11(1.6)$ & $14(8.9)$ & \\
\hline & Treatment for surgical infection & $606(72.4)$ & $489(71.9)$ & $117(74.5)$ & \\
\hline & $\begin{array}{l}\text { Treatment for surgical infection, } \\
\text { Prophylaxis }\end{array}$ & $1(0.1)$ & $1(0.1)$ & $0(0)$ & \\
\hline \multirow[t]{4}{*}{ SSI classification } & Deep incisional & $34(4.1)$ & $0(0)$ & $34(21.7)$ & \\
\hline & No SSI & $680(81.2)$ & $680(100)$ & $0(0)$ & \\
\hline & Organ/space & $28(3.3)$ & $0(0)$ & $28(17.8)$ & \\
\hline & Superficial incisional & $95(11.4)$ & $0(0)$ & $95(60.5)$ & \\
\hline Clavien-Dindo & Grade I & $92(11)$ & $86(12.6)$ & $6(3.8)$ & \multirow[t]{6}{*}{$<0.0001$} \\
\hline \multirow[t]{5}{*}{ Classification } & Grade II & $133(15.9)$ & $72(10.6)$ & $61(38.9)$ & \\
\hline & Grade III & $48(5.7)$ & $8(1.2)$ & $40(25.5)$ & \\
\hline & Grade IV & $45(5.4)$ & $19(2.8)$ & $26(16.6)$ & \\
\hline & Grade V & $69(8.2)$ & $46(6.8)$ & $23(14.6)$ & \\
\hline & None & $450(53.8)$ & $449(66)$ & $1(0.6)$ & \\
\hline Reoperation & & $80(9.6)$ & $19(2.8)$ & $61(38.9)$ & $<0.0001$ \\
\hline Readmission & & $45(5.4)$ & $18(2.7)$ & $27(17.2)$ & $<0.0001$ \\
\hline 30-day mortality & & $70(8.4)$ & $47(6.9)$ & $23(14.6)$ & 0.002 \\
\hline
\end{tabular}

SSI: Surgical site infection; LOS: length of stay; GI: gastrointestinal; RBCU: red blood cell unit; *including appendicitis, cholecystitis \& diverticulitis.

\section{Discussion}

Our study demonstrated that the incidence of SSI in patients who underwent ES in a single unit during a 5-year period was $18.7 \%$, with $E$. coli being the most frequently isolated pathogen. Patients who developed SSI were, in accordance to what has been reported in the literature, older, had higher BMI, had more comorbidities, and underwent more severe surgical procedures, which lasted longer and had contaminated wounds more frequently compared to those who did not develop SSIs.

American Society of Anesthesiology performance status scoring was an independent predictor for the occurrence of SSI. Van Walraven et al. demonstrated a similar outcome in a study, which investigated risk factors of SSI using the
National Surgical Quality Improvement Program (11), while Mezemir et al. showed that patients with ASA class I had decreased likelihood of developing SSI $(\mathrm{OR}=0.3)$ compared to ASA class III patients (12). Khan et al. demonstrated a similarly strong association of ASA score and SSI rates in clean and clean-contaminated wounds of surgical patients (13). A large international prospective multicenter study, which included a total of 12,539 patients who underwent gastrointestinal surgery, 1,538 (12.2\%) of whom developed SSI also demonstrated that ASA scores II and III were independently associated with SSI (14).

Operative time is a potentially modifiable risk factor, in contrast to other inherent or acquired risk factors such as chronic kidney dysfunction, pulmonary obstructive diseases, 


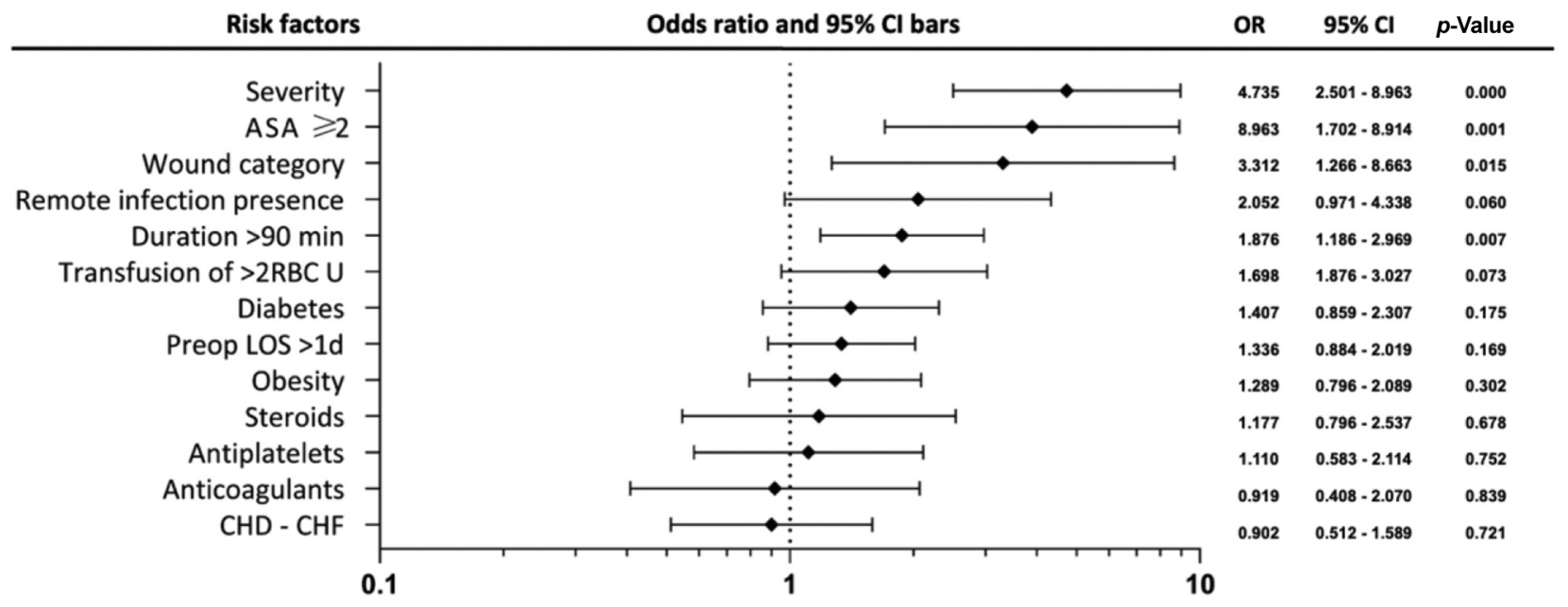

OR: Odds ratio; Cl: confidence intervals; ASA: American society of anesthesiology score; RBC: red blood cells; CHD; coronary heart disease; CHF: congestive heart failure; CKD: chronic kidney disease.

Figure 2. Multivariable logistic regression analysis for the presence of surgical site infections.

or diabetes mellitus. In addition, it is also influenced by several other factors such as surgical experience and operative planning. Our analysis confirmed the detrimental role of prolonged operative time in causing SSIs. Such outcome is in line with the findings of several prospective and retrospective studies throughout multiple surgical disciplines and different types of procedures (15-17). A recently published systematic review and meta-analysis demonstrated a statistically significant association between operative time and occurrence of SSI (16). Although the included studies covered a wide range of surgical procedures, based on their pooled analysis, the authors showed that the likelihood of developing SSI was twice as high among individuals who underwent surgical procedures with protracted operative times. Lastly, Li et al. also showed that surgical duration $>120$ minutes was independently associated with development of SSI in patients undergoing emergency abdominal surgery (18). Therefore, the adoption of measures such as improved operative planning, whenever possible, is of paramount importance.

Several inherent limitations to our study should be acknowledged. In particular, there was significant heterogeneity among the surgical procedures undertaken. Furthermore, there is no widely accepted international classification of severity of ES procedures, thus our classification may be subject to bias. Nevertheless, these criteria were predetermined and all patients were independently assessed by two surgeons to ensure adherence to our criteria. Moreover, our study evaluated only a certain number of risk factors, which however have been previously validated in the literature, thus other potential risk factors, patient-, procedureor perioperative care-associated, may remain elusive.

Identification of patients at risk for developing SSI is critical, because reduction of SSI can reduce the associated morbidity and mortality. Interdisciplinary cooperation between surgeons, anesthesiologists, infectious diseases specialists, operative theater and nursing staff is crucial for achieving the best possible outcomes in this high-risk group of patients. As patient safety is of utmost importance in the practice of surgery nowadays and as patients undergoing ES are more vulnerable and at higher risk of developing SSI, every surgical unit should audit their outcomes in order to pinpoint modifiable risk factors.

\section{Conflicts of Interest}

The Authors declare that they have no competing interests in relation to this study.

\section{Authors' Contributions}

Conception and design: AP, MS, CV, GLD; Acquisition of data: AP, CC, EM, DB; Analysis and interpretation: MS, NM, GT; Drafting the manuscript: AP, NM, SK, CC, DB; Revising the manuscript: NM, MS, GT, CV, GLD; Final approval for submission: all Authors.

\section{References}

1 De Simone B, Sartelli M, Coccolini F, Ball CG, Brambillasca P, Chiarugi M, Campanile FC, Nita G, Corbella D, Leppaniemi A, Boschini E, Moore EE, Biffl W, Peitzmann A, Kluger Y, Sugrue M, Fraga G, Di Saverio S, Weber D, Sakakushev B, Chiara O, 
Abu-Zidan FM, Ten Broek R, Kirkpatrick AW, Wani I, Coimbra R, Baiocchi GL, Kelly MD, Ansaloni L and Catena F: Intraoperative surgical site infection control and prevention: a position paper and future addendum to WSES intra-abdominal infections guidelines. World J Emerg Surg 15(1): 10, 2020. PMID: 32041636. DOI: 10.1186/s13017-020-0288-4

2 Global Guidelines for the Prevention of Surgical Site Infection. WHO Guidelines Approved by the Guidelines Review Committee, Geneva, 2016. Available at: https://www.who.int/ gpsc/global-guidelines-web.pdf?ua $=1$ [Last accessed on September 13, 2021]

3 Pinkney TD, Calvert M, Bartlett DC, Gheorghe A, Redman V, Dowswell G, Hawkins W, Mak T, Youssef H, Richardson C, Hornby S, Magill L, Haslop R, Wilson S, Morton D, West Midlands Research Collaborative and ROSSINI Trial Investigators: Impact of wound edge protection devices on surgical site infection after laparotomy: multicentre randomised controlled trial (ROSSINI Trial). BMJ 347: f4305, 2013. PMID: 23903454. DOI: 10.1136/bmj.f4305

4 Uchino M, Ikeuchi H, Matsuoka H, Takahashi Y, Tomita N and Takesue Y: Surgical site infection and validity of staged surgical procedure in emergent/urgent surgery for ulcerative colitis. Int Surg 98(1): 24-32, 2013. PMID: 23438273. DOI: 10.9738/ CC83.1

5 Dominioni L, Imperatori A, Rotolo $\mathrm{N}$ and Rovera F: Risk factors for surgical infections. Surg Infect (Larchmt) 7 Suppl 2: S9-12, 2006. PMID: 16895516. DOI: 10.1089/sur.2006.7.s2-9

6 Aga E, Keinan-Boker L, Eithan A, Mais T, Rabinovich A and Nassar F: Surgical site infections after abdominal surgery: incidence and risk factors. A prospective cohort study. Infect Dis (Lond) 47(11): 761-767, 2015. PMID: 26114986. DOI: 10.3109/ 23744235.2015.1055587

7 National Healthcare Safety Network Surgical Site Infection Event. Available at: https://www.cdc.gov/nhsn/pdfs/pscmanual/ 9pscssicurrent.pdf [Last accessed on September 13, 2021]

8 Altemeier WA, Burke JF, Pruitt BA and Sandusky WR: Manual on Control of Infection in Surgical Patients. 2nd Ed. Philadelphia: Lippincott Williams \& Wilkins, 1984.

9 Doyle DJ and Garmon EH: American Society of Anesthesiologists Classification (ASA Class). StatPearls, Treasure Island (FL), 2020.

10 Ortega G, Rhee DS, Papandria DJ, Yang J, Ibrahim AM, Shore AD, Makary MA and Abdullah F: An evaluation of surgical site infections by wound classification system using the ACS-NSQIP. J Surg Res 174(1): 33-38, 2012. PMID: 21962737. DOI: $10.1016 /$ j.jss.2011.05.056
11 van Walraven $\mathrm{C}$ and Musselman $\mathrm{R}$ : The surgical site infection risk score (SSIRS): A model to predict the risk of surgical site infections. PLoS One 8(6): e67167, 2013. PMID: 23826224. DOI: $10.1371 /$ journal.pone.0067167

12 Mezemir R, Seid A, Gishu T, Demas T and Gize A: Prevalence and root causes of surgical site infections at an academic trauma and burn center in Ethiopia: a cross-sectional study. Patient Saf Surg 14: 3, 2020. PMID: 31921353. DOI: 10.1186/s13037-0190229-x

13 Khan M, Rooh-ul-Muqim, Zarin M, Khalil J and Salman M: Influence of ASA score and Charlson Comorbidity Index on the surgical site infection rates. J Coll Physicians Surg Pak 20(8): 506-509, 2010. PMID: 20688013. DOI: 08.2010/JCPSP.506509

14 GlobalSurg Collaborative: Surgical site infection after gastrointestinal surgery in high-income, middle-income, and low-income countries: a prospective, international, multicentre cohort study. Lancet Infect Dis 18(5): 516-525, 2018. PMID: 29452941. DOI: 10.1016/S1473-3099(18)30101-4

15 Lee JS, Terjimanian MN, Tishberg LM, Alawieh AZ, Harbaugh CM, Sheetz KH, Holcombe SA, Wang SC, Sonnenday CJ and Englesbe MJ: Surgical site infection and analytic morphometric assessment of body composition in patients undergoing midline laparotomy. J Am Coll Surg 213(2): 236-244, 2011. PMID: 21601491. DOI: 10.1016/j.jamcollsurg.2011.04.008

16 Cheng H, Chen BP, Soleas IM, Ferko NC, Cameron CG and Hinoul P: Prolonged operative duration increases risk of surgical site infections: a systematic review. Surg Infect (Larchmt) 18(6): 722-735, 2017. PMID: 28832271. DOI: 10.1089/sur.2017.089

17 Smith BP, Fox N, Fakhro A, LaChant M, Pathak AS, Ross SE and Seamon MJ: "SCIP"ping antibiotic prophylaxis guidelines in trauma: The consequences of noncompliance. J Trauma Acute Care Surg 73(2): 452-6; discussion 456, 2012. PMID: 22846955. DOI: $10.1097 / \mathrm{TA} .0 \mathrm{~b} 013 \mathrm{e} 31825 \mathrm{ff} 670$

$18 \mathrm{Li}$ Z, Li H, Lv P, Peng X, Wu C, Ren J and Wang P: Prospective multicenter study on the incidence of surgical site infection after emergency abdominal surgery in China. Sci Rep 11(1): 7794, 2021. PMID: 33833359. DOI: 10.1038/s41598-021-87392-8

Received August 25, 2021

Revised September 10, 2021 Accepted September 13, 2021 